\title{
An individual drug-therapy and genetic testing report of temporal bone verrucous carcinoma
}

This article was published in the following Dove Press journal:

OncoTargets and Therapy

4 September 2014

Number of times this article has been viewed

\section{Haolei Tan \\ Yong Liu \\ Gangcai Zhu \\ Leiming $\mathrm{Pi}$ \\ Donghai Huang \\ Xin Zhang}

Department of Otolaryngology Head and Neck Surgery, Xiangya Hospital, Central South University, Changsha, People's Republic of China
Correspondence: Xin Zhang

Otolaryngology Major Disease Research Key Laboratory of Hunan Province, 87 Xiangya Road, Changsha, Hunan 410008, People's Republic of China

Email xinzh99@yahoo.com
Objective: To investigate the pathology and pathogenesis of and treatment methods for temporal bone verrucous carcinoma.

Materials and methods: A single-patient report of verrucous carcinoma on the left external auditory canal is presented and analyzed along with all cases of temporal bone verrucous carcinoma that have been documented in the English literature.

Results: Most of the patients with verrucous carcinoma of the temporal bone have histories of surgery, trauma, or infection, and verrucous carcinomas are sensitive to antimicrotubule chemotherapeutic medicines. Adjuvant radiation therapy is not effective, but surgical treatment might be relatively more effective.

Conclusion: Temporal bone verrucous carcinoma has a poor prognosis; therefore, the preferred treatment is surgical resection facilitated with antimicrotubule chemotherapeutic treatment. Adjuvant radiation therapy is not a preferred treatment for temporal bone verrucous carcinoma.

Keywords: verrucous carcinoma, temporal bone, drug therapy, genetic testing

\section{Introduction}

Verrucous carcinomas were first reported in 1948 by Ackerman, ${ }^{1}$ and are tumors that rarely present in the head or neck, but commonly present in the oral cavity and larynx. Verrucous carcinomas have also been reported in other parts of the head, such as the sinus, ${ }^{2}$ nose, pharynx, ${ }^{3}$ scalp, ${ }^{4}$ and esophagus. ${ }^{5}$ This disease rarely occurs in the temporal bone, ${ }^{6}$ and thus far only 17 cases have been reported in the English-language literature. The patient we report on in this paper is the 18 th.

Verrucous carcinoma is histologically classified as a well-differentiated squamous cell carcinoma. ${ }^{7}$ Verrucous carcinoma cells are larger than squamous cell carcinoma cells, exhibit reduced mitotic activity, are only located in the basal layer, and sometimes contain visible small intraepithelial abscesses. The superficial portions of verrucous carcinomas are similar to those of other general verrucae, which may only exhibit symptoms of hyperkeratosis, hyperplasia, or papilloma. The keratinocyte cell is well differentiated, with a pompadour cytoplasm and a pale and small nucleus. This carcinoma can be treated as a part of the papillary damage that evolves from the papilloma. ${ }^{8}$

We observed and analyzed one case of papilloma wart-like cancer of the left ear canal. The main purpose of this paper is to increase awareness of this rare disease. Furthermore, we are among the first to report on the use of chemotherapy-related gene detection in this disease. 


\section{Materials and methods}

A search for all of the reports of verrucous carcinomas of the temporal bone, middle ear, and external auditory canal in the English-language literature yielded only 17 cases. Our report adds more information for future research into verrucous carcinomas of the temporal bone. Comprehensive analyses were also performed on disease histories, clinical presentations, examinations, treatments, and prognoses to compare our case to those in the previous reports.

\section{Drug-therapy genetic testing}

A sample was fixed in formalin prior to paraffin embedding. One hematoxylin and eosin-stained slide was selected and deoxyribonucleic acid (DNA) was extracted from corresponding unstained $10 \mu \mathrm{m}$-thick slides by manual microdissection. The tissue DNA was isolated by automated extraction using the BioRobot M48 (Qiagen) following the manufacturer's instructions. Quality and quantity of isolated DNA was assessed by agarose gel electrophoresis. Pyrosequencing was performed with the BRAF Pyro Kit (Qiagen) detecting certain mutations. One microliter of each isolated DNA was analyzed. Pyrosequencing was performed on the PyroMark Q24 platform (Qiagen). Pyrograms were generated with the PyroMark Q24 software, and data were analyzed manually by Qiagen. Sequences surrounding the site of interest served as normalization and reference peaks for quantification and quality control. Gene sequences were as follows: GSTP1 wild-type target, AATACATCTCC; mutation-type target, AATACGTCTCC; $X R C C 1$ wild-type target, TCTGGGAGGGC; mutationtype target, TCT-CGGAGGGC; CYP1B1 wild-type target, CACTGAA; mutation-type target, CAGTGAA; MDR1 G2677AT wild-type target, TGCTGGGAACCT; mutationtype target, TA/TCTGGGAAGGT.

\section{Results}

A 51-year-old female who had undergone surgery on an external auditory canal papilloma 4 years previously presented with a 1-month history of pain and suppuration in the left preauricula.

A clinical examination revealed the following: the top of the tragus had a sinus and local skin irritation, inside of which was a visible ulceration; the external auditory canal had stenosis and swelling, and a large amount of purulent secretion was present; and the eardrum was not clear and had a hole of two fingerbreadths. There were no palpable lumps or swollen lymph nodes on the neck.
An early pathologic examination from another hospital revealed that the left external auditory canal had two masses, each of which was approximately $5 \mathrm{~mm}$ in diameter. Microscopic examination revealed polypoid hyperplasia, squamous cell hyperplasia, and further cell infiltration (Figure 1A). The second pathological examination revealed that sinus scrapings from the left tragus consisted of broken squamous epithelia, the proliferation of which was accompanied by parakeratosis and keratosis, and inflammatory granulation tissue, which had been infiltrated by neutrophils, lymphocytes, and plasma cells, and was full of foreign-body giant cells (Figure 1B and C). Computed tomography (CT) examination revealed the following: the soft tissue of the left ear canal and the surrounding area were swollen; the area near the parotid had a visible soft-tissue mass of approximately $3 \times 2 \mathrm{~cm}$, with small pieces of high-density shadows; the external auditory canal was narrow; and the density of the left parotid gland was slightly elevated (Figure 2A and B). Bad patency was observed in the left external ear canal on magnetic resonance imaging (MRI) performed at our hospital (Figure 2C and D). The patient underwent surgery that consisted of left free vastus lateralis flap repair and resections of the left external expansion, left external, mass and left parotid. During the surgery, the left external auditory canal was found to be filled with gray tumor tissues that pushed forward, destroyed the bone, reached the superficial and deep-lobe parotidectomies, and pushed dorsally to the zygomatic arch, with inflammation and destruction of the bone. The pathology results revealed censorship of the left external auditory canal with squamous papilloma-like proliferation. Some epithelia had mild atypia. There was more subepithelial inflammatory cell infiltration that was similar to that of a wart-like cancerous change (Figure 1D). The examined tissues had signs of left parotid chronic inflammation and mild atypia squamous cell nests.

MRI examination of this patient 2.5 months after surgery revealed irregular expansion of the left ear canal and partial bone agenesis in the temporal bone scales and the external auditory canal in the posterior walls of the anterior and temporomandibular joints (combined with results from CT) (Figure 2E and F). Positron emission tomography (PET)/CT examination revealed an abnormal radioactive uptake shadow in the corresponding parts with a maximum standardized uptake value of 4.1. Small flaky soft-tissue shadow was found filling the left eardrum room and the mastoid air, and PET revealed light radioactive uptake shadows in the corresponding parts with a maximum standardized uptake value of 2.2. The development of the brain was normal, and no abnormalities in 

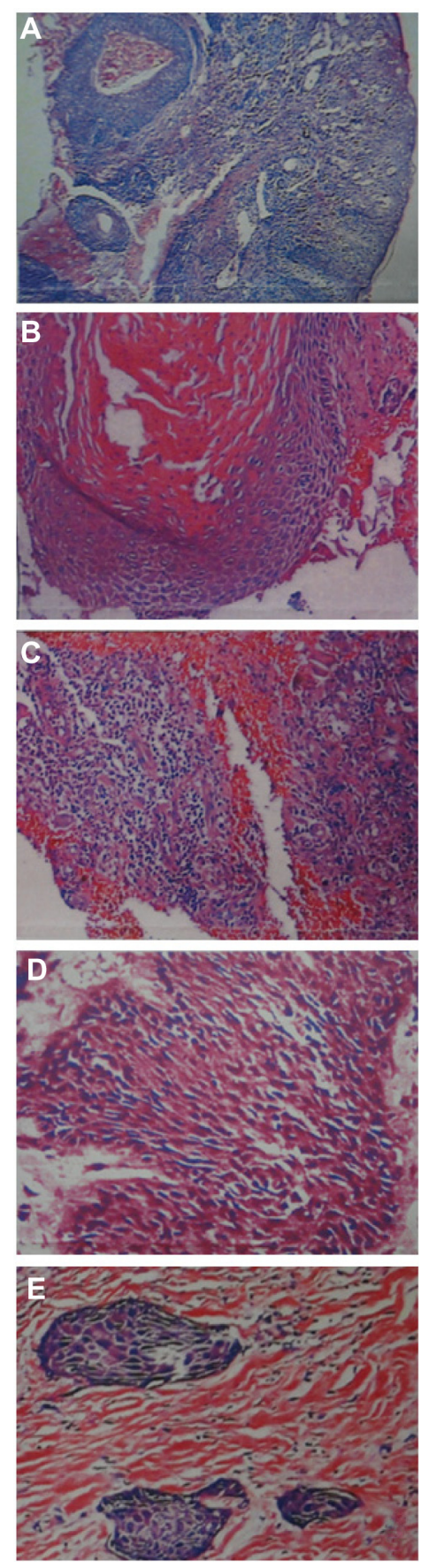

Figure I (A) Polypoid hyperplasia, squamous cell hyperplasia, and additional cell infiltration. (B and C) Squamous epithelial hyperplasia with parakeratosis and keratosis, excessive granulation tissue with further neutrophil infiltration of lymphocytes and plasma cells, and foreign-body giant-cell reaction. (D) Squamous papilloma-like proliferation, mild atypia of the epithelia and further subepithelial inflammatory cell infiltration that was similar to that of a wart-like cancer. (E) Welldifferentiated squamous cell carcinoma.

brain density or radioactive distribution were observed. Due to the high possibility of postoperative local residuals (Figure 3), the patient underwent radiotherapy in another hospital.

Two months after radiotherapy, the patient's left ear exhibited a nodule that gradually increased in size, and the surface of this nodule ultimately ruptured and overflowed with visible white residue (Figure 4A). Consequently, she came to our hospital for another surgery. Pathology results revealed papilloma-like material and a verrucous carcinoma. Two months after the surgery, the canal wall and the back of the left ear were tumorous and purulent. Samples were taken from the tumor-surface tissue for pathologic examination, the results of which revealed a highly differentiated squamous cell carcinoma in the left external auditory canal (Figure 1E). Sixteen months after the first surgery (ie, after 13 months of radiotherapy), most of the left temporal lobe and the frontal, parietal, and occipital lobes had been invaded by tumors, and she ultimately died of respiratory and circulatory failure.

\section{Discussion \\ Literature analysis}

Thus far, 17 cases of temporal bone verrucous carcinoma have been reported in the English literature. Based on a combination of the survey works of Strojan et $\mathrm{al}^{9}$ and Miller et al, ${ }^{10}$ all reported cases are summarized in Table 1.

\section{Inspection}

Of the previous 18 cases, three underwent combined radiotherapy/chemotherapy treatment, two died, and one was followed up for 18 months with no recurrence. In our case, the patient experienced recurrence within a short period after the surgery and radiotherapy, and was thus recommended for combination chemotherapy. A tumor-individualized drug-therapy genetic test was performed on this patient prior to this treatment that used the blood DNA-extraction and pyrosequencing method. The GSTP1, XRCC1, CYPIB1, and $M D R 1$ genes were examined (Figure 5). The test results suggested the following:

- The GSTP1 gene was homozygous wild type with normal enzymatic activity. The chemotherapy drug was cleared quickly. An increased dose or alternate medicine should be used when using platinum-based drug-treatment programs. ${ }^{22}$

- The $X R C C 1$ gene was homozygous mutant with reduced DNA-repair functionality. ${ }^{23}$ This gene was not sensitive to platinum-based chemotherapy drugs, ${ }^{24}$ and thus chemotherapy programs with platinum-based drugs ${ }^{25}$ are not recommended.

- The CYP1B1 gene was homozygous wild type and capable of functioning correctly in chemotherapy programs with antimicrotubule drugs. 

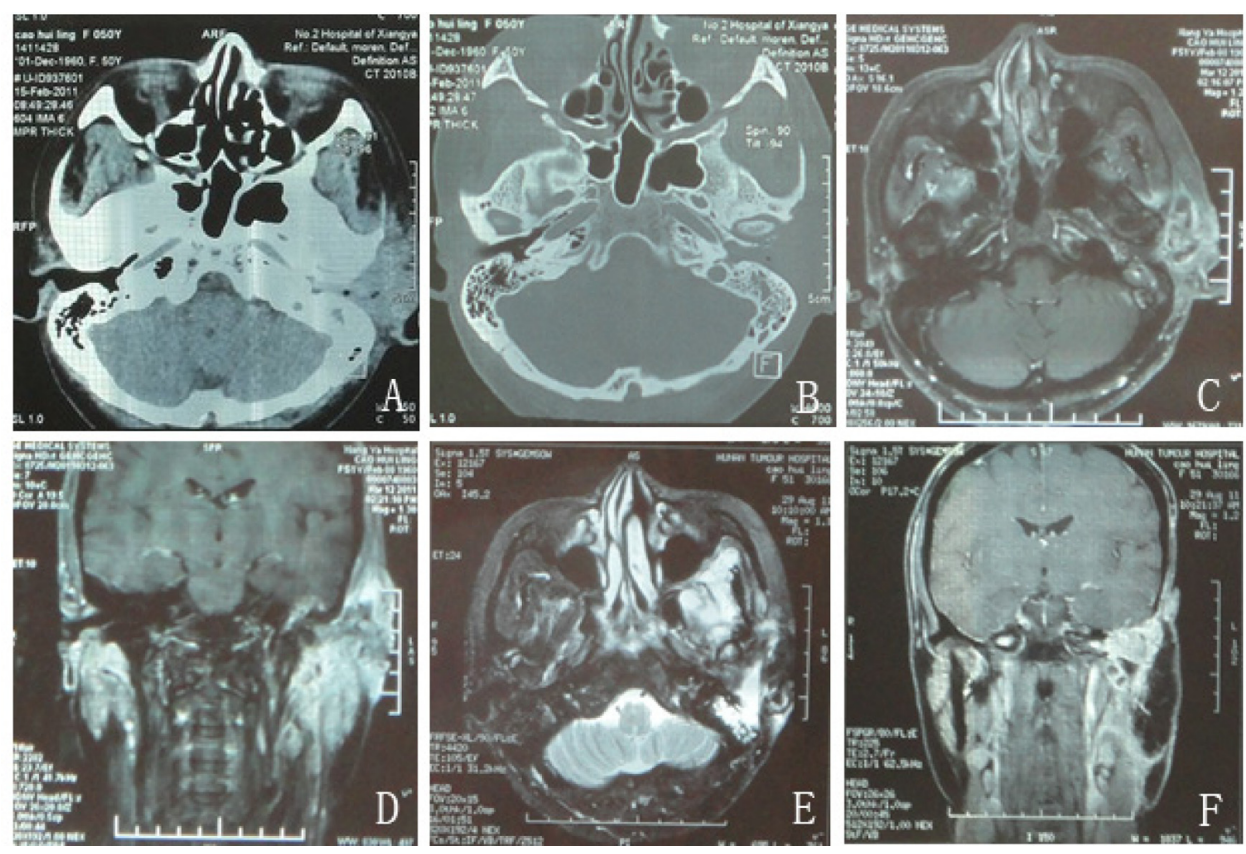

Figure 2 (A and $\mathbf{B}$ ) Computed tomography examination prior to the first surgery in our hospital. (C and $\mathbf{D})$ Magnetic resonance imaging examination prior to the first surgery in our hospital. (E and $\mathbf{F})$ Magnetic resonance imaging examination prior to chemotherapy.

- The MDR1 G2677 A/T gene was heterozygous mutant with reduced transportation activity, ${ }^{26}$ and might have been sensitive to antimicrotubule medicine. Chemotherapy programs with antimicrotubule drugs are recommended.

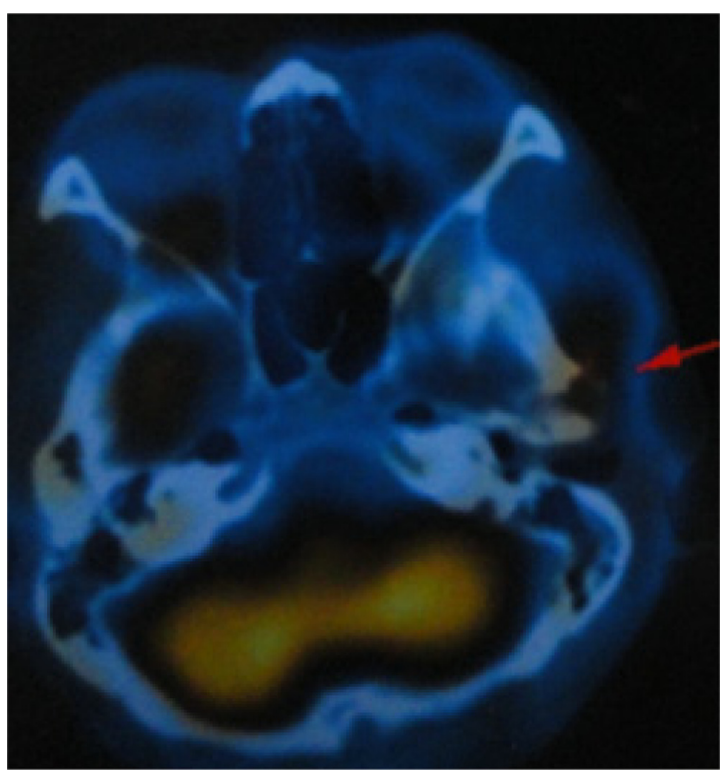

Figure 3 Positron emission tomography/computed tomography examination. Notes: The left external auditory canal exhibited no abnormal density mass levels, with the exception of the radioactive uptake shadow in the local regions of the thickened soft tissue in the temporal region, which were equivalent to the local bone thinning observed on the left temporal bone drum unit in the corresponding portions of the abnormal uptake shadow, shadow. Red arrow: positron emission tomography examination revealed the abnormal uptake shadow on the left temporal bone, which had a maximum standardized uptake value of 4.1 .
Our report is the first to provide detection results about verrucous carcinoma chemotherapy drug therapy-related genes. We believe chemotherapeutic drugs of the antimicrotubule class might have been effective; however, we did not use such drugs in this case because of the patient's status. Although these results might be individual-specific, they still provide a good reference for future chemotherapies for temporal bone verrucous carcinomas.

\section{Treatment and prognosis}

Of the three cases that underwent combined radiotherapy/ chemotherapy treatment, two died, and one was followed up for 18 months and exhibited no recurrence. Four cycles
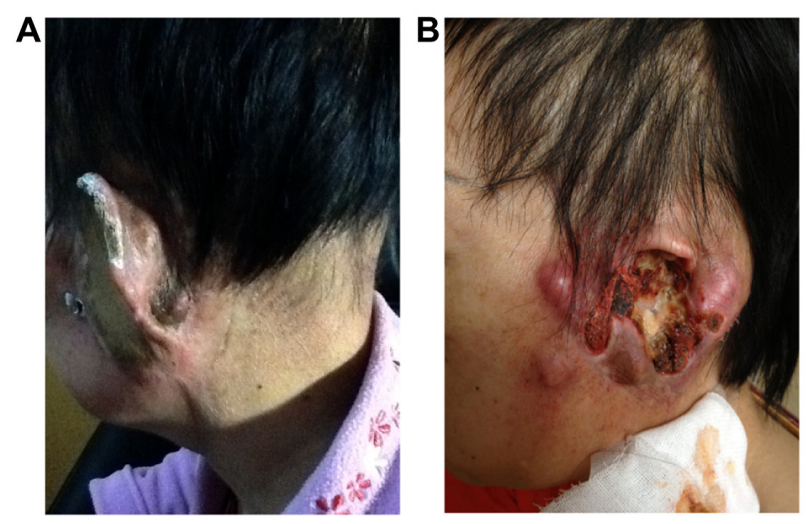

Figure 4 (A) Two months after radiotherapy, the tumor relapsed. (B) Four months after the surgery, the patient suffered more progression of tumor on the left ear and the left temporal lobe. 
Table I Cases of temporal bone verrucous carcinoma published in the English literature

\begin{tabular}{|c|c|c|c|}
\hline Study & Site & Treatment & Result \\
\hline Ferlito et al" & External auditory canal & No report & No report \\
\hline Orsini et $\mathrm{al}^{12}$ & Left and middle ear & Surgery + radiotherapy & No recurrence after 7 months \\
\hline Woodson et $\mathrm{al}^{13}$ & Right temporal bone & Surgery + radiotherapy & No report \\
\hline Proops et $\mathrm{al}^{14}$ & Right temporal bone & Radiotherapy + chemotherapy & No recurrence after 18 months \\
\hline \multirow[t]{5}{*}{ Edelstein et $\mathrm{al}^{15}$} & Left and middle ear & Surgery & No recurrence after 10 years \\
\hline & Right external auditory canal & Surgery & No recurrence after 5 years \\
\hline & Left external auditory canal & Surgery & $\begin{array}{l}\text { No recurrence after } 4 \text { years after } \\
\text { the second surgery }\end{array}$ \\
\hline & Right temporal bone & $\begin{array}{l}\text { Surgery }+ \text { radiotherapy }+ \\
\text { chemotherapy }\end{array}$ & Dead after II months \\
\hline & Right temporal bone & Surgery + radiotherapy & Dead after I year \\
\hline Stafford and & Right external auditory canal & Surgery & No recurrence after 18 months \\
\hline Frootko 16 & & & after the second surgery \\
\hline Diengdoh et $\mathrm{al}^{17}$ & Right temporal bone & Surgery & Dead after 8 months \\
\hline Farrell and Dowe ${ }^{18}$ & Right temporal bone & Surgery & Dead after 8 months \\
\hline Kletzker et al ${ }^{19}$ & Temporal bone & Surgery & No recurrence at 3 years \\
\hline Hagiwara et $\mathrm{al}^{20}$ & Right temporal bone & No therapy & Dead after 20 months \\
\hline Pleat et $\mathrm{al}^{21}$ & Right temporal bone & Surgery & Dead after 2 months \\
\hline Strojan et al $^{9}$ & Left temporal bone & Radiotherapy + chemotherapy & Died of bronchitis \\
\hline Miller et al ${ }^{10}$ & Right external auditory canal & Surgery & No report \\
\hline Present case & Left external auditory canal & Surgery + radiotherapy & Dead after 16 months \\
\hline
\end{tabular}

of chemotherapy administered as prolonged intravenous infusions of vinblastine, methotrexate, and bleomycin were applied, and this case died of bronchitis ${ }^{9} 11$ years later. After the treatment of the antimicrotubule drug vinblastine, the patient got a better prognosis. In Proops et al's report, ${ }^{14}$

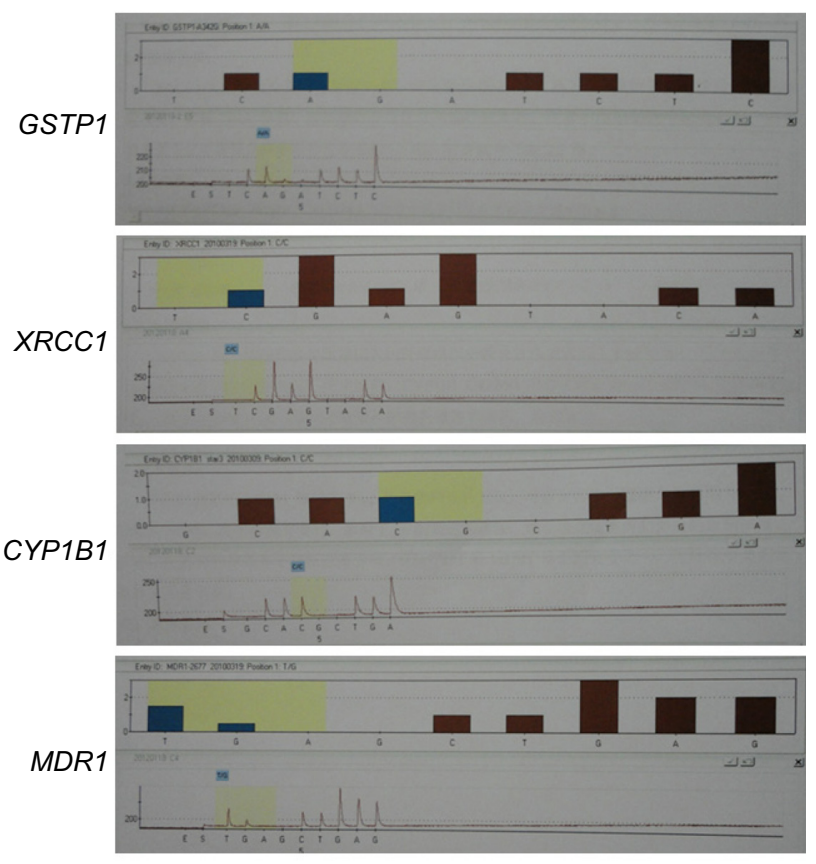

Figure 5 Tumor-individualized drug-therapy genetic test.

Notes: GSTPI, homozygous wild-type; XRCCI, homozygous mutant; CYPIBI, homozygous wild type; MDRI, G2677A/T genotype-heterozygous mutant. 5-fluorouracil and mitomycin $\mathrm{C}$ were used to treat the patient. Although no recent reports of recurrence (18 months), this case lacks longer follow-up data. In Edelstein's case ${ }^{15}$ using carboplatin-paclitaxel chemotherapy, there was a recurrence after 3 months and the patient died after 11 months. It was just as our individualized drug-therapy genetic tests showed: chemotherapy programs with platinum-based drugs are not recommended. Although the patient in our case did not undergo chemotherapy treatment, the chemotherapy medication genetic testing results showed that this patient was not sensitive to platinum-based chemotherapy medicine, but was sensitive to antimicrotubule-based medicine. We believe chemotherapy treatment can be effective for the treatment of temporal bone verrucous carcinoma, and recommend antimicrotubule-based medicines.

A large amount of controversy surrounds the choice of surgery or radiotherapy for the treatment of verrucous carcinoma. At its early stage, radiotherapy was not as effective as surgery. ${ }^{27}$ Analysis of these medical reports also suggests that even with combined radiotherapy, the 5-year survival rate was still low. ${ }^{28}$ Worse, radiotherapy might convert the tumor into an aggressive squamous cell carcinoma. ${ }^{21}$ However, some authors have reported that no cell anaplasia was observed in patients treated with radiotherapy, and only $7 \%$ of patients treated with radiotherapy exhibit cell anaplasia. ${ }^{29,30}$ Some patients who were treated with surgery but not radiotherapy still exhibited similar anaplasia. 
Our report is the first to provide detection results about verrucous carcinoma chemotherapy drug-related genes and provide a new supporting example for the perspective that radiotherapy can convert verrucous carcinomas into more aggressive squamous cell carcinoma. The first two surgical pathology reports were identified as verrucous carcinoma (Figure 1D); however, after two surgeries and radiotherapy, the external auditory canal tumor recurred, and examination of the pathological tissue revealed highly differentiated squamous cell carcinoma (Figure 1E).

In conclusion, due to the poor prognosis of temporal bone verrucous carcinoma, we recommend treatment via surgical resection supplemented with chemotherapy with antimicrotubule medicines. Radiotherapy with platinum-based medicine should not be the preferred treatment.

\section{Disclosure}

The authors report no conflicts of interest in this work.

\section{References}

1. Ackerman LV. Verrucous carcinoma of the oral cavity. Surgery. 1948;23(4):670-678.

2. Yiotakis J, Vamvakidis T, Iakovou E, Manolopoulos L. Aggressive verrucous carcinoma of the paranasal sinuses invading the orbit: case report and literature review. J Laryngol Otol. 2009;123(11):e23.

3. Jahn AF, Walter JB, Farkashidy J. Verrucous carcinoma of the nasopharynx -a clinicopathologic case report. J Otolaryngol. 1980;9(1): 84-89.

4. Pattee SF, Bordeaux J, Mahalingam M, Nitzan YB, Maloney ME. Verrucous carcinoma of the scalp. J Am Acad Dermatol. 2007; 56(3):506-507.

5. Lagos AC, Marques IN, Reis JD, Neves BC. Verrucous carcinoma of the esophagus. Rev Esp Enferm Dig. 2012;104(8):443-445.

6. Thompson L. World Health Organization classification of tumours: pathology and genetics of head and neck tumours. Ear Nose Throat J. 2006;85(2):74.

7. Ferlito A, Devaney KO, Rinaldo A, Putzi MJ. Papillary squamous cell carcinoma versus verrucous squamous cell carcinoma of the head and neck. Ann Otol Rhinol Laryngol. 1999;108(3):318-322.

8. Suarez PA, Adler-Storthz K, Luna MA, El-Naggar AK, Abdul-Karim FW, Batsakis JG. Papillary squamous cell carcinomas of the upper aerodigestive tract: a clinicopathologic and molecular study. Head Neck. 2000;22(4):360-368.

9. Strojan P, Soba E, Gale N, Auersperg M. Verrucous carcinoma of the temporal bone and maxillary antrum: two unusual presentations of a rare tumor. Onkologie. 2006;29(10):463-468.

10. Miller ME, Martin N, Juillard GF, Bhuta S, Ishiyama A. Temporal bone verrucous carcinoma: outcomes and treatment controversy. Laryngoscope. 2010;120 Suppl 4:S169.

OncoTargets and Therapy

\section{Publish your work in this journal}

OncoTargets and Therapy is an international, peer-reviewed, open access journal focusing on the pathological basis of all cancers, potential targets for therapy and treatment protocols employed to improve the management of cancer patients. The journal also focuses on the impact of management programs and new therapeutic agents and protocols on
11. Ferlito A, Antonutto G, Silvestri F. Histological appearances and nuclear DNA content of verrucous squamous cell carcinoma of the larynx. ORL J Otorhinolaryngol Relat Spec. 1976;38(2):65-85.

12. Orsini MA, Conner GH, Sharkey FE. Verrucous carcinoma of the middle ear. Trans Pa Acad Ophthalmol Otolaryngol. 1981;34(1):86-88.

13. Woodson GE, Jurco S 3rd, Alford BR, McGavran MH. Verrucous carcinoma of the middle ear. Arch Otolaryngol. 1981;107(1):63-65.

14. Proops DW, Hawke WM, van Nostrand AW, Harwood AR, Lunan M. Verrucous carcinoma of the ear. Case report. Ann Otol Rhinol Laryngol. 1984;93(4 Pt 1):385-388.

15. Edelstein DR, Smouha E, Sacks SH, Biller HF, Kaneko M, Parisier SC. Verrucous carcinoma of the temporal bone. Ann Otol Rhinol Laryngol. 1986;95(5 Pt 1):447-453.

16. Stafford ND, Frootko NJ. Verrucous carcinoma in the external auditory canal. Am J Otol. 1986;7(6):443-445.

17. Diengdoh JV, Leeming RD, Shaw MD. Verrucous carcinoma of the base of the skull. Br J Neurosurg. 1990;4(1):73-76.

18. Farrell ML, Dowe AC. Verrucous carcinoma of the temporal bone. Aust N Z J Surg. 1995;65(3):214-216.

19. Kletzker GR, Smith PG, McIntire LD, Leonetti JP. Presentation and management of uncommon lesions of the middle ear. Am J Otol. 1995;16(5):634-642.

20. Hagiwara H, Kanazawa T, Ishikawa K, et al. Invasive verrucous carcinoma: a temporal bone histopathology report. Auris Nasus Larynx. 2000;27(2):179-183.

21. Pleat JM, Bradley M, Orlando A, Rigby H. Verrucous carcinoma of the temporal bone: a wolf clothed in wool. Skull Base. 2004;14(1): $39-46$.

22. Yong WP, Innocenti F, Ratain MJ. The role of pharmacogenetics in cancer therapeutics. Br J Clin Pharmacol. 2006;62(1):35-46.

23. Rosell R, Lord RV, Taron M, Reguart N. DNA repair and cisplatin resistance in non-small-cell lung cancer. Lung Cancer. 2002;38(3):217-227.

24. Wei Q, Frazier ML, Levin B. DNA repair: a double-edged sword. J Natl Cancer Inst. 2000;92(6):440-441.

25. Buters J, Quintanilla-Martinez L, Schober W, et al. CYP1B1 determines susceptibility to low doses of 7,12-dimethylbenz[a]anthracene-induced ovarian cancers in mice: correlation of CYP1B1-mediated DNA adducts with carcinogenicity. Carcinogenesis. 2003;24(2):327-334.

26. Yusuf RZ, Duan Z, Lamendola DE, Penson RT, Seiden MV. Paclitaxel resistance: molecular mechanisms and pharmacologic manipulation. Curr Cancer Drug Targets. 2003;3(1):1-19.

27. Koch BB, Trask DK, Hoffman HT, et al. National survey of head and neck verrucous carcinoma: patterns of presentation, care, and outcome. Cancer. 2001;92(1):110-120.

28. Huang SH, Lockwood G, Irish J, et al. Truths and myths about radiotherapy for verrucous carcinoma of larynx. Int $J$ Radiat Oncol Biol Phys. 2009;73(4):1110-1115.

29. Tharp MN, Shidnia H. Radiotherapy in the treatment of verrucous carcinoma of the head and neck. Laryngoscope. 1995;105(4Pt1):391-396.

30. Miyazawa T, Aida S, Shima K. Hemorrhagic cerebellar anaplastic glioma appearing 12 years after prophylactic cranial radiotherapy for acute lymphocytic leukemia. Neurol Med Chir (Tokyo). 2008;48(3):126-130.

\section{Dovepress}

patient perspectives such as quality of life, adherence and satisfaction. The manuscript management system is completely online and includes a very quick and fair peer-review system, which is all easy to use. Visit http://www.dovepress.com/testimonials.php to read real quotes from published authors. 